\title{
Determinant of Food Security Within the COVID-19 Epidemic Circumstances- A Special Case of Chinese Agriculture Food Production and Distribution Industries
}

\author{
Apurbo Sarkar \\ Northwest A\&F university https://orcid.org/0000-0001-6520-9217 \\ Anamika Kor Peau \\ Northwest A\&F University: Northwest Agriculture and Forestry University \\ Asif Abdullah Al \\ Xian Jiaotong University: Xi'an Jiaotong University \\ Lu Qian ( $\square$ luqian@nwafu.edu.cn ) \\ Northwest A\&F University \\ Jiban Chandro Das \\ Northwest A\&F University: Northwest Agriculture and Forestry University
}

\section{Research}

Keywords: Food Security, key-aspects, Production, Distribution, SEM, Determinants

Posted Date: November 4th, 2020

DOI: https://doi.org/10.21203/rs.3.rs-99760/v1

License: (c) (1) This work is licensed under a Creative Commons Attribution 4.0 International License.

Read Full License 


\section{Abstract}

\section{Purpose}

Since the outbreak of the COVID-19 epidemic rises, it poses a catastrophic effect for the society and its development globally. These pandemic situations put global inhabitants under tremendous pressure to maintain a sufficient supply of nutrition and desirable food security. Agricultural food production and distribution industries may play a vital role in determining the current conditions of any countries food security and sustainable development goals.

\section{Design/methodology/approach}

Since an increasing number of people had been suffering from hunger and malnutrition before even the infection strikes, it could create more dangerous circumstances by creating a global food crisis if the immediate measure is not taken. This paper examines the determinants of food security within three distinct aspects (effective utilization of food, food availability, and food access) within the COVID-19 epidemic situation. For developing and validating the model, the empirical data was collected from the agricultural food supply industry in China (Shaanxi Province). Whereas, the core analytical assumption has made by employing the exploratory factor analysis (EFA), confirmatory factor analysis (CFA), and structural equation modelling (SEM).

\section{Findings}

After analyzing the data collected from 67 agricultural food productions and distribution personnel along with the hypothesis testing, it has found that determinants of the effective utilization if food aspects are positively related to the determinants of food availability and food access aspects, and the determinants of food availability are positively related to the food access determinants.

\section{Originality}

This research will be helpful to the government and industry in developing policies and strategies for the successful implementation of all the associated determinants of food security in terms of the epidemic situation.

\section{Highlights}

- The nexus amongst determinants of food security is carefully assessed.

- Determinants for food utilization are positively related to the determinants of food availability and food access.

- The determinants of food availability are positively related to food access determinants.

\section{Introduction}


Since the epidemic of COVID-19 spread out, some apparent changes in regional food systems and most other agricultural production factors like the supply of manure, fertilizers, energy, pesticides, seeds, and shortens of labour become visible. As a result, this possible earning and transition losses are supposed to create intense pressures and threatened food security in several regions of the world. Sound production and supplies of agricultural food have a strong influence on mitigating global food and nutritional requirements and maintaining the smooth development goal of the UN (Akinleye et al., 2020). The World Food Program of the United Nations has claimed approximately 265 million people are at risk of severe food insecurity by the end of the year 2020, rise from 135 million inhabitants well before catastrophe (Sumner et al., 2020). As purchasers have now become limited and suppliers ignore collaborating with growers, the food producers often face significant losses from nutritious and perishable food products. Currently, several nations and enterprises are imposing extra initiatives to secure the smooth transition of agricultural production and distribution. It helps the government combat the possible food scarcity and maintain adequate supplies of reasonably priced \& nutritious meals within the COVID-19 pandemic circumstances. So that general customers and inhabitants can still reach and buy food considering the imposed constraints on travel and income losses. The possible impacts due to COVID-19 circumstances are portrayed in figure one (Fig. 1)

Due to flourishing agricultural and distribution sectors, China is continuously holding a leading position towards the global food supply chain (Duggan and Naarajärvi, 2015). However, the recent outbreak of the novel coronavirus (COVID-19) has dramatically changed the global and local scenarios (Espitia et al., 2020). From the beginning of the COVID-19 outbreak, the Chinese government imposed a stringent lockdown policy. The effects of these epidemic situations are usually many, but two significant components of the food supply chain (production and distribution) are severely exaggerated by this cataphoric virus outbreak (Hossain, 2020). For maintaining effecting lockdown, several measures and controls are imposed on people's mobility, transport of agricultural inputs found limited and shortens the supply of labour, which potentially could cause disruptions in the agriculture production sector. From producer to consumer, from local buyers to wholesale, and from cross-regional shipping to city consumption, almost every channel of the agricultural product supply chain has been interrupted (FAO, 2020a; Stephens et al., 2020). Moreover, agro-products' diminished consumer demand arises from strict lockdown and sudden shutdown of restaurants, local markets, and caterers, resulting in enormous proportions of unsellable seasonal perishable vegetables and fruits backlogged even unpicked in the farmland eventually (Barichello, 2020). If such devastating problems could not be appropriately addressed, farmers would not gain any profit from the current harvesting that would also be troublesome for them to reinvest in the next spring plantation, resulting in vast constraints in next season growth. According to FAO (2020b, p. 19), the cumulative impacts of COVID-19 outbreak have put the whole world in threatened conditions of food security and nutritional deficiencies, whereas the conditions of the countries with a large population are most critical. In summary, it can be stated confidently that, due to this serious circumstances the determinants of food security should be measure accordingly and structurally for providing a clear overview. 
In order to provide a clear overview of any countries food security, the prime issues that should be evaluated are what determinants quantify the FS as a complete and integrated system. Furthermore, the determinants should be measured and structured with some statistical tools for its better interpretations. In this article, FS's approaches are quantified with several determining factors and indicators, which are categorized into three main aspects (effective food utilization, food access, and food availability) for a more precise representation of the proposed model. Those determinants play an active role in quantifying the effective measures for securing sufficient and nutritious food. Due to the recent outbreak of COVID19 , those determinants are facing continuous alterations. Therefore, the evaluation, incorporation, and assessment of these determinants are the first priority for maintaining desirable FS.

Figure 1. Possible impacts of Covid-19 on the food supply chain (Kim et al., 2020).

The prime objectives of this paper are to identify the determinants associated with securing the food supply and demand popularly known as food security (FS), construct an integrated framework of these determinants by utilizing some robust statistical tools, and finally test the framework with structural equation modelling (SEM) tactics. This paper examines the three aspects of the determinants of food security (effective utilization of food, food availability, and food access) within the COVID-19 epidemic situation. The rest of the article is designed as: the following parts highlighted the evaluations of the associated determinants of FS accompanied by the empirical methodologies of the articles in section three. Section four is portraits for the interpretation of the result, followed by the discussion section. Lastly, section five (conclusions) has been comprised of concluding remarks of the study.

\section{Evaluations Of The Determinants Of Fs}

Within the last few years, there are several studies have been interpreted for measuring FS (Barrett, 2010; Zhou, 2010), COVID-19 and FS (Montalvao and Van de Velde, 2020), FS and Human Mobility (Choudhury et al., 2020; Zhang et al., 2018), the impact of COVID-19 on food and nutrition security (Nyamwanza and Sinyolo, 2020), Food Insecurity, and COVID-19 (Wolfson and Leung, 2020, p. 19), food systems and FS (Bakalis et al., 2020), the determinants of FS (Bolarinwa et al., 2020; lese et al., 2019; Le et al., 2013) and so on. By a careful evaluation and summarization of the contributions and findings of those individual articles, this study proposed a framework for quantifying food security within the circumstances of COVID-19.

After evaluating the Tasmanian food sector, Le et al. (2013) stated, price, quality, variety, physical access, financial access, social supports, knowledge, food purchase, food consumption, coping strategies are prime determinants that can quantify the food security. Sassi (2012) found food access, food price, income, food availability, food production, conditions of cash crop, available resources, domestic food stock, imports, and aid are found as crucial determinants after a critical evaluation of Malwai. Food imports, resources, production, income, available hop, adequacy of nutritional foods, and distributional channels are comprised as determinants by Lese et al. (2019). By evaluating food consumption patterns and dietary diversity, Firdaus \& Cahyono (2017) found purchasing power, market \& trade, processing \& 
distributions, market infrastructure, finance \& investments, economic situation, and political situations have an essential effect in food security. Price, availability in outlets, social support, financial resources, transportation facilities, mobility, nutritional knowledge, storage facilities, varieties, locations of food outlets, promotions, and quality of food, are drawn by George \& McKay (2019) within the Indian food security and public distribution channel. Circumstances, price, economic solvency, production, storage \& food stock, processing, transport \& market, income, distributions, knowledge, food quality, food safety \& adequacy, poverty, and purchasing power are set as crucial determinants by Mohr et al. (2016). Transportation, the supply of food, productive resources, households stocks, purchasing power, associated resources of purchasing, access to markets, transport, available and accessible basic desirable food, level of knowledge, processing \& storage facilities, diverse food, changes in circumstances, and challenges like changing climate can act key factors for determining FS of any country (Gray, 2020, p.; Maniriho and Bizoza, 2018; Santeramo, 2015). By exploring the conditions of the foo security within Mareko District, Guraghe Zone, Southern Ethiopia, Tefera \& Tefera (2014) listed sales of livestock, seasonal migration, off-farm (agricultural employment), borrow grain or cash from relatives, food aid, mortgaging land, and rent out the land are comprised as determinant as determinants of FS.

The proportion of studies examined might have indeed been expanded because many of the explored studies are focused on several prior-literatures. The careful assessment of publications demonstrates that studies related to the FS determinants have been mostly centred on empirical-based. Quantitative evaluations by scholars with various socio-economic dimensions and regions have contributed to several names of the determinants. These distinct names of the determinants need to be formatted and structured accordingly in order to give the domain proper guidance. Likewise, a standardized category of determinants has been established by a critical evaluation of these published studies. Evaluation of those determinants has been thoroughly discussed with industry experts and academicians working in the food production and distribution field. For better interpretation and more precise understanding, some names of those determinants are modified and altered according to the suggestions gathered from the discussion. In the context of fulfilling the objectives of this study, we comprised 15 determinants that can quantify the FS standards and represents the current situations of China in terms of maintaining FS Which are: "Price of food, Production, Varieties of food, Proper distribution channel, Diverse \& variety of retails options, Purchase, Processing, Consumption, Changing strategies, (Skill, knowledge, and references), Physical access, financial access, Markets/infrastructures, Social supports, and Timing." After that, these 15 drivers are categorized within three dimensions (food availability, food access, and effective utilization of food).

The critical evaluation of the reviewed studies revealed that most of the studies had developed the determinants based on prior literature. Furthermore, fewer authors have verified the determinants by the use of statistical instruments. Besides that, no investigator has constructed a framework of determinants that reflects their interconnection of the determinants. This article is designed to address this gap in the literature by developing a framework quantifying the determinants of FS based on CFA and SEM tactics. Moreover, there is a very limited number of studies have been traced that can quantify the food security within the context of the COVID-19 circumstance as the investigation of the food production and 
distribution industry is also mostly ignored by previous studies. A well-structured framework and exploration of relationships among the determinants of FS within the context of COVID-19 circumstances are the main innovation of this paper.

Figure 2. Steps of the current study. Adopted and modified from Sarkar et al. (2020).

\section{Research Methodology}

Both qualitative (anti-positivism) and quantitative (positivism) methodologies (approach) was utilized for fulfilling the objectives of this current study. The basic steps and methodology are designed with the indicators development, framework design, questionnaire development, and validation of the framework. The identification of drivers is made by critical analysis of published papers and discussion held with some practitioners. For the starting points of this analysis, we comprised 15 determinants from an indepth literature investigation of several published peer-reviewed journal articles, books, regional and international reports along with some discussion with some professors and industry professionals. For developing and validating the model, the empirical data was collected from the agricultural food supply industry in China (Shaanxi Province). Whereas, the core analytical assumptions are made by employing the exploratory factor analysis (EFA), confirmatory factor analysis (CFA), and structural equation modelling (SEM). The prime steps associated with the methodology of current research are portraits in figure number three (Fig.3). Different practitioners widely utilize these types of Methodologies for a similar framework (Cheah et al., 2010; Kumar Mittal and Singh Sangwan, 2014; Voon et al., 2011). The brief descriptions of each method are stated below:

\subsection{Survey instrument development}

By focusing on the determinants portrayed over the last segment, a structured survey questionnaire was developed. In the questionnaire, respondents were asked to assess how significant the determinants are for quantifying the FS on five-point Likert scale feedback, where 2 denotes very less effect, and 10 denotes very substantial effects. This component of measure is often utilized within a similar domain since it explored the same interval between the specific calculation value and interval scale is estimated as well as it assisted with some other convenient quantitative analysis (Kumar Mittal and Singh Sangwan, 2014). According to Voon et al. (2011), for effective evaluation of the respondent's personal judgment, these types of questionnaires should be employed. The questionnaire is designed with two parts. Within the first part, all the demographic information of the respondents was gathered, and the second part is consists of the rating option for the determinants. A sample questionnaire was presented in figure three (Fig.3).

Fig.3. Example of the questionnaire used.

\subsection{Data collection}


A structured questionnaire was disseminated via email, and We Chat apps with a detailed explanation of the objectives of the study, followed by the telephonic discussion that was held to find out the relationship among the identified determinants. The data was collected between May to June 2020. In the initial stage of our survey, we encountered with low response rate. For this, a follow-up mail and telephonic call were made to increase the response rate. From 150 polls, we finally get 67 usable fully filled questionnaires, which were further used for the interpretation of the SEM model.

\subsection{Data analysis}

According to Cafiero et al. (2014), determinants will be more useful for future scholarly materials and policy measures if those are statistically reliable and well structured. Reliability represents the capacity of the attribute to respond consistently. The inner precision could be assessed by utilizing various composite reliability paradigms like Cronbach's a. Inner cohesion evaluation has been performed through the Social Science Statistical Package (SPSS) to determine the reliability of the component within each category in terms of Cronbach's a. According to Taber (2018), for the composite reliability measurement, a values higher than 0.70 are widely recommended for satisfying the inner consistency. If necessary, some items are terminated for improving the Cronbach's a.

If the driver can quantify the theoretical framework for which it has been assigned to test, it can be assumed that it has construct validity. For doing so, we employed factor analysis as a tool to evaluate the determinants and measuring the construct's validity, whereas it might be involved in providing a consistent evaluation of measurements as suggested by related literature. Factors analysis is chosen, as our study is intended to develop and evaluates the determinants of food security in particular epidemic circumstances. The assessment of the minimum set of samples per attribute always defines the adequacy of findings of factor analysis. Tanaka (1987) and Babatunde \& Qaim (2010) suggested that, for securing the statistical significance, the study should be evaluated with a data set of at least 30 observations. The adequacy of the factor model is calculated by evaluating the frequency of the innerrelationship between components/factors. We found three significant tactics, i.e., Correlation matrix, Barlett's test of sphericity, and Kaiser-Meyer-Oklin (KMO), which are mostly recommended in related literature measuring the adequacy of samples (Abafita and Kim, 2014; Hair et al., 1998).

\section{Results And Discussion}

The interpretation of the results is carried out with two-step procedures, i.e., framework proposition and framework validation which is covered within the section 4.1 and 4.2. We employed Explanatory factor Analysis (EFA) for the framework proposition and validation the framework is confirmed by Confirmatory Factor Analysis (CFA) and Structural Educational Modeling (SEM) tactics.

\subsection{Common Method Bias Test}

Since all of the elements in the survey were estimated with a specific form of the respondent (from food production and distribution industries) and a five-point Likert scale, a typical methodological bias may, 
therefore, exist throughout this analysis. Thereby, the effect of the common method bias has been sincerely evaluated. While there are just a limited number of forecasts that are present for determining the impact of common method bias (Tehseen et al., 2017), we adopted two approaches to defining the issues of common bias, i.e., Exploratory factor analysis and Harman's single-factor test.

\subsubsection{Exploratory factor analysis}

Exploratory factor analysis (EFA) is a mainstream structured process that is required for evaluating the identified and endogenous factors at the interval or ratio level (Austin and Calderón, 1996). In terms of the framework's factor loadings, we assessed all the latent determinants, as shown in table 1 . The early period of the assessment usually contains a wide range of provisional determinants. Thus factor rotation should be done for transforming the initial level factors for a better interpretation of results (Kumar Mittal and Singh Sangwan, 2014). For performing the principal components analysis, this study used the varimax rotation tactics. According to Mumtaz \& Parahoo (2019), for measuring inner precisions and Harman's Single factor test and exploratory factor analysis (EFA) could be useful to measure a single measurement of the indicators for the rest of the mechanisms. The assessment of the measurement system could be quantified with the conceptual modelling to determine the interdependencies and interconnections among variables $X$ (effective utilization of food), $Y$ (food availability), and $Z$ (food access). The evaluation furthermore verified that the items of the scales used were representative of the study. A satisfactory level of inner relationship (factor loadings) has been found among the determinants and their categories.

\section{Table 1: Exploratory factor analysis}

The Kaiser-Meyer Olkin (KMO) measure of the indicators has been found as 0.797 , which denotes more than the required minimum values of 0.6 (Lindell and Whitney, 2001; Torabizadeh et al., 2020). Bartlett's test of sphericity of significance $(P=0.02)$ implies that the research could have been perceived by a credible measurement model with statistical importance of $p<0.05$, as suggested by Lindell \& Whitney (2001). The preliminary report (table 1 ) also implies that the indicators have Bartlett's sphericity $\left(\chi^{2}\right)$ score (1023.256), with a $28 \%$ degree of freedom and significance level of 0.020 .

Table 2 Descriptive statistics and factor analysis (within each factor)

Corrected item-total correlation (CITC) denotes the correspondence of a component or factor which measured with a composite score of the entire set of the remaining component within the same set. Table three proves that all the determinants a well ahead from the recommended CITIC value of 0.50 (Koufteros, 1999). Table three also shows that the determinants possessed a mean value within 3.61 to 4.0000 amongst the five scales. This implies that the observation considered the assessed determinates as a valuable assumption for securing food supply and security. By assessing the Cronbach's a-value, the reliability and viability of the determinants have been assured. Table three denotes CAID values for all the determinants that are well above the recommended CAID values, as stated by P. Barrett (2007a). 


\subsubsection{Harman's single-factor test}

Within the context of the study, we applied "Harman's single-factor test," as compiled by Podsakoff et al. (2003) and Tehseen et al. (2017). In this research, the principal component analysis (PCA) and unrevealed correlation matrix were employed with the entire latent construct included in this research to evaluate if a single factor arises or a single factor accounted for more than $50 \%$ of the co-variation. The measurements revealed that the overall variance accounted for $66.092 \%$ of the five factors from fifteen determinants, whether the first indicators hold with $49.028 \%$ variance within the dataset. Overall interpretation of table 2 shows that the dataset does not contain any single factor bias issues, and the values of the first factors also did not lead with the most variance. After concluding all the preliminary assessments of table one, two, and three, it can be confidently stated that all the collected data are viable and valid for further analytical approaches.

Table 3 Harman's single factor test

\subsection{Confirmatory factor analysis (CFA)}

In the last sub-section, we utilized the EFA for evaluating the association amongst the latent and measured variables. Further, we utilized CFA for providing a substantial assessment of the construct's uniformity, as Koufteros (1999) suggested EFA is not profound for confirming the theory or proposed framework. As an essential part of SEM tactics, CFA is a multivariate analytical framework that investigates the uni-dimensionality of the casual association amongst the latent and measured variables in a prior established model derived from theory (Mueller and Hancock, 2001). Which is crucial since weak correlations amongst conceptual factors and observed variables might cause inaccurate assumptions and creates confusion for the interpretation of the relationships within the theoretical framework (Koufteros, 1999). The observations have been transmitted to CFA by employing the AMOS (Moment Analysis Structure) statistical tool. As per the uniform and unregulated regression measurements, the findings of the observations are presented in table 2 . Within the unstructured regression measurements, the values of the regression of a single item under all uniformed variables are specified, and the rest of the other variables are assumed. The regression values of "physical access, purchase, and price of food" are randomly specified. The unstandardized value of the correlation implies that the component raises the non-standardized value of the correlation against "the endogenous variable by $1 "$.

On the other hand, structured regression values imply that if the latent factor increases by " 1 standard deviation", then the standard deviation of each factor also increased by the structured regression values in contrast to that element (Kumar Mittal and Singh Sangwan, 2014). Table 2 confirms that for our framework minimum value of standard error is 3.892 , which is much higher than the minimum accepted weight (|2|) of "critical ratio" for the variable estimate. |2| is often recommended for testing the significance at the 0.01 level, as stated by Huddleston-Casas et al. (2009) and Mittal \& Sangwan (2014). The framework might have standardized regression values of attributes ranging from 0 to 1 . The higher the value is, the better the identified factors represent the latent factor. The findings show that all the 
determinants hold more values than 0.6 , which implies all the determinants reasonably signify the projected latent factors.

The measurement model was tested by using the MLE (maximum likelihood estimation), where 59 degrees of freedom (DF) and $X^{2}$ (CMIN)-value of 152.81 has been found. The ratio of $X^{2}$ to DF comes out to be 2.59, which is far below the highest suggested weight of 5 (Kumar Mittal and Singh Sangwan, 2014). The $p$-value of $<0.001$ illustrated that the findings are statistically substantial, with more than $99 \%$ level of confidence. The goodness of fit index value is 0.829 , and the comparative fit index value is 0.853 , which denotes that the findings of the CFA fit our proposed framework. The root means the square error of the approximation value is 0.09 (recommended value close to zero), and the root mean square residual value is 0.07 (recommended value $<0.08$ ). Moreover, the latent covariance generally ranges binary from " 0 " to " 1 ", by which " 0 " implies the considerations are distinct, and " 1 " implies that the overall considerations seem to be the same. The association and variance values for food availability and food access aspects are 0.659 and 0.407 , for effective utilization of food and food availability aspects are 0.465 and 0.298 , and between effective utilization of food and economy are 0.508 and 0.475 , respectively. The conclusion was, therefore, to approve (verify) the convergent validity and ready for thoroughly assessing with the structural framework to validate the ultimate framework of the determinants.

Table 4 A statistical representation of Confirmatory factor analysis

\subsection{Structural model}

As EFA and CFA aimed to examine the single relationship at one time, but for better interpretation of the framework, there is an emergence to test all the relationships within the same period (Barrett, 2007b). As multivariate analytical tools, SEM is designed to provide a complete relationship building within the proposed framework. The current study covers a combination of latent variables and observed variables. Thus we employed these tactics utilized both the factor analysis and multiple regression analysis, and it can produce or test the structural relationship amongst the observed variables and latent paradigms as recommended by Kelloway (1995). It is also considered a confirmatory tactic to confirm any proposed model or framework, and it starts with the proposition of hypothesis, which is intended to test (Kumar Mittal and Singh Sangwan, 2014).

Table 5 Results of the hypothesis test

Therefore, within the context of the CFA analysis, we proposed three hypotheses $(H 1, H 2$, and $H 3)$ intending to examine the full structural framework. For providing statistical representation, we utilized the AMOS tool as recommended by Blunch (2012), and the findings are compiled in table five. Since our observation is relatively limited, we employed the maximum likelihood estimation (MLE) approaches for presenting a better estimation. Hair et al. (2006) guided that MLE can be used for analysis with a small set, even with 50 observations. The estimated loading represents a similar interpretation with the CFA framework that denotes the explored parameter holds sufficient stability and validity of the proposed 
framework. Table five represents the findings of hypothesis testing. As $p$-values are smaller than 0.05 , and $\beta$ value is positive for all three hypotheses. Therefore the proposed framework represents the satisfactory level and well-structured as recommended by Hair et al. (2006) and Cheah et al. (2010). The inner relationship among the determinants and the structural representation of the proposed framework are portrayed in figure number four (Fig.4). The framework shows that the determinant for effective utilization of food is positively related to the determinants of food availability and food access, and the determinants of food availability are positively related to the food access determinants.

Fig.4 Complete SEM framework for the determinants of FS

\section{Conclusions}

Agriculture, food production, and distribution industries may possess an active role in determining the conditions of any countries sustainable development goals and food security (FAO, 2017). As the crisis of global food security is increasing day by day, triggering a recent devastating outbreak of the CIVID-19 virus, the conditions of agricultural production and distributions are interrupted mainly. Without a proper and well-coordinated intervention accompanied by subsequent mitigating steps, the cumulative consequences of COVID-19 and other inevitable global crises (global warming, climate change, and resource shortage), the operations of global and local food security will fall into severe threats in the long run. The food security determinants should have been appropriately measured for the bitterness of global viability and attaining sustainable development goals. This study constructs a statistically valid and reliable framework that can quantify the determinants of FS within the circumstances of the COVID-19 outbreak. The 15 reliable and valid determinants of FS are extracted from an in-depth literature investigation varied from several published peer-reviewed journal articles, different books, and various reports, along with some discussion confined with professors, and industry professionals are distributed into three aspects (effective utilization of food, food availability, and food access) by the use of using SPSS statistical tool. The framework has been verified with the help of SEM tactics. Hypotheses encourage a positive and substantial connection amongst the identified dimensions as those are evaluated with the help of the data set collected from the Chinese agricultural food production and distribution industries. The hypothesis test implies that the three aspects of food security mainly work as an integrated manner, which means these are interrelated with each other. In other words, the effective utilization of food aspects is the root factor in this dynamic relationship as it connected with both the aspects, as shown in figure four (Fig. 4). Moreover, from hypothesis testing, it can be seen that the accessibility aspects set dimensional effects within the food availability aspects. That means maintaining desirable food security; the interaction amongst determinants should be highlighted and carefully handled by the policymaker. The significance of this analysis is, it establishes the nexus within the determinant of FS, by which policymakers can make efficient use and leverage the root determinants for availing the food security within local as well as global aspects. This study provided a recent theoretical overview of the determinants of FS with a special focus on food production and distribution industries within the COVID-19 epidemic circumstances. Decision-makers must keep working within the food production and distribution industries to predict, recognize, and resolve potential challenges. This 
critical situation arises from the COVID-19 outbreak could be a better opportunity for the government to plan or initiate the implementation of the long-awaited reformation of the existing agriculture product supply to the more digital paradigm.

The study compiles the following recommendation for the policymaker for better transition of food security within the circumstances of COVID-19:

- A transition towards digital farming and platforms will also intensify, and Asian developing nations will have to deal with this changing setting in order to improve the productivity of the agricultural sector.

- The changes will also reorient the positions of government and industry entities in terms of agricultural development, consumer safety, the transportation systems of the distribution chain, quality management, and growth. Sufficient resources and profit should be allocated through agricultural modernization among the small-scale farmers and low-income agriculture populations.

- Eventually, structural reforms will encourage new jobs opportunity, the competitiveness of the economy, governance, and regulation of food quality to ensure food security for poor and small farmers.

As the framework is developed using the data gathered within the context of recent outbreaks of COVID19 and a merging nation, there is a possibility of data heterogeneity. The study is focused within a specific area, and with a limited number of observations gathered, the framework could be potential for further exploration with a wide range of sectors and scenarios. Moreover, if the framework can test within the contexts of different regions and with the endures of agriculture food products, it would have been more exciting.

\section{List Of Abbreviations}




\begin{tabular}{|ll|}
\hline Word & Abbreviation \\
\hline EFA & Exploratory Factor Analysis \\
\hline CFA & Confirmatory Factor Analysis \\
\hline SEM & Structural Equation Model \\
\hline UN & United Nations \\
\hline FAO & Food And Agriculture Organization Of The United Nations \\
\hline FS & Food Security \\
\hline SPSS & Social Science Statistical Package \\
\hline KMO & Kaiser-Meyer-Oklin \\
\hline CITC & Corrected Item Total Correlation \\
\hline CAID & Continuous Assessment of Interpersonal Dynamics \\
\hline PCA & Principal Component Analysis \\
\hline AMOS & Moment Analysis Structure \\
\hline DF & Degrees Of Freedom \\
\hline CMIN & Chi-Square Statistics \\
\hline
\end{tabular}

\section{Declarations}

\section{Acknowledgements}

The authors thank Professor Zhong Feng Su and Professor Li Hua from School of Management, Xian Jiaotong University for their exceptional guidance and prior review of the article. We the authors want to extent our gratitude anonymous reviewer for their valuable inputs to make the article up to the mark.

\section{Transparency declarations}

Not associated within the article.

\section{Authors' contributions}

AS designed the study, screened the paper, extracted and analyzed data, wrote the manuscript. AKP compile the data and wrote the manuscript. LQ arranged the questionnaire, reviewed the manuscript, arrange the funding, and approved the final manuscript as submitted. AAA and JCD screened the paper, collected and compiled the data as well as initiated the post contact with the respondent for further inputs. 


\section{Funding}

LQ arrange the fund supported by grants from National Natural Science Foundation of China (Grant No: 71973105).

\section{Availability of data and materials}

Data will be provided under request to the corresponding author.

\section{Ethics approval and consent to participate}

Not applicable.

\section{Consent for publication}

All the authors give their authorization to publish the article.

\section{Competing interests}

The authors declare that they have no competing interests.

\section{References}

Abafita, J., Kim, K.-R., 2014. Determinants of Household Food Security in Rural Ethiopia: An Empirical Analysis. J. Rural Dev.-Gyeongje 37, 129-157. https://doi.org/10.22004/ag.econ.196613

Akinleye, O., Dauda, S., Oladoyin, R., Iwegub, O., 2020. Impact of COVID-19 Pandemic on Financial Health and Food Security: a Survey-Based Analysis. O Popogbe 00 Impact COVID-19 Pandemic Financ. Health Food Secur. Surv.-Based Anal. June 42020.

Austin, J.T., Calderón, R.F., 1996. Theoretical and technical contributions to structural equation modeling: An updated annotated bibliography.

Babatunde, R.O., Qaim, M., 2010. Impact of off-farm income on food security and nutrition in Nigeria. Food Policy 35, 303-311. https://doi.org/10.1016/j.foodpol.2010.01.006

Bakalis, S., Valdramidis, V., Argyropoulos, D., Ahrne, L., Chen, J., Cullen, P.J., Cummins, E., Datta, A.K., Emmanouilidis, C., Foster, T., 2020. How COVID-19 changed our food systems and food security paradigms. Curr. Res. Food Sci.

Barichello, R., 2020. The COVID-19 pandemic: Anticipating its effects on Canada's agricultural trade. Can. J. Agric. Econ. Can. Agroeconomie.

Barrett, C., 2010. Measuring Food Security. Science 327, 825-8. https://doi.org/10.1126/science.1182768 
Barrett, P., 2007a. Structural equation modelling: Adjudging model fit. Personal. Individ. Differ., Special issue on Structural Equation Modeling 42, 815-824. https://doi.org/10.1016/j.paid.2006.09.018

Barrett, P., 2007b. Structural equation modelling: Adjudging model fit. Personal. Individ. Differ. 42, 815824.

Blunch, N., 2012. Introduction to structural equation modeling using IBM SPSS statistics and AMOS. Sage.

Bolarinwa, O.D., Ogundari, K., Aromolaran, A.B., 2020. Intertemporal evaluation of household food security and its determinants: evidence from Rwanda. Food Secur. 12, 179-189. https://doi.org/10.1007/s12571019-00986-z

Cafiero, C., Melgar-Quiñonez, H.R., Ballard, T.J., Kepple, A.W., 2014. Validity and reliability of food security measures. Ann. N. Y. Acad. Sci. 1331, 230-248.

Cheah, W.L., Manan, W., Zabidi-Hussin, Z., 2010. A structural equation model of the determinants of malnutrition among children in rural Kelantan, Malaysia.

Choudhury, P., Koo, W., Li, X., Kishore, N., Balsari, S., Khanna, T., 2020. Food Security and Human Mobility During the Covid-19 Lockdown. Harv. Bus. Sch. Technol. Oper. Mgt Unit Work. Pap. 20-113.

Duggan, N., Naarajärvi, T., 2015. China in Global Food Security Governance. J. Contemp. China 24, 943960. https://doi.org/10.1080/10670564.2015.1013381

Espitia, A., Rocha, N., Ruta, M., 2020. Covid-19 and Food Protectionism.

FAO, 2020a. Mitigating risks to food systems during COVID-19: Reducing food loss and waste. FAO, Rome, Italy. https://doi.org/10.4060/ca9056en

FAO, 2020b. Adjusting business models to sustain agri-food enterprises during COVID-19. FAO, Rome, Italy. https://doi.org/10.4060/ca8996enAlso Available in:Chinese Spanish Arabic French Russian

FAO, F., 2017. The future of food and agriculture-Trends and challenges, Annual Report. Food and Agriculture Organisation Rome.

Firdaus, N., Cahyono, B.D., 2017. How Food Consumption Pattern and Dietary Diversity Influence Food Security: Evidence From Di YOGYAKARTA and East Nusa Tenggara. J. Ekon. Pembang. LIPI 25, 27-38. https://doi.org/10.14203/JEP.25.1.2017.27-38

George, N.A., McKay, F.H., 2019. The Public Distribution System and Food Security in India. Int. J. Environ. Res. Public. Health 16, 3221. https://doi.org/10.3390/ijerph16173221

Gray, R.S., 2020. Agriculture, transportation, and the COVID-19 crisis. Can. J. Agric. Econ. Can. Agroeconomie 68, 239-243. https://doi.org/10.1111/cjag.12235 
Hair, J.F., Black, W.C., Babin, B.J., Anderson, R.E., Tatham, R.L., 2006. Multivariate data analysis 6th Edition. Pearson Prentice Hall N. J. Hum. Crit. Reformul. J. Abnorm. Psychol. 87, 49-74.

Hair, J.F., Black, W.C., Babin, B.J., Anderson, R.E., Tatham, R.L., 1998. Multivariate data analysis. Prentice hall Upper Saddle River, NJ.

Hossain, S.T., 2020. Impacts of COVID-19 on the Agri-food Sector: Food Security Policies of Asian Productivity Organization Members. J. Agric. Sci. Lanka 15.

Huddleston-Casas, C., Charnigo, R., Simmons, L.A., 2009. Food insecurity and maternal depression in rural, low-income families: a longitudinal investigation. Public Health Nutr. 12, 1133-1140.

lese, V., Paeniu, L., Pouvalu, S., Nand, M., 2019. Food Security: Best Practices from the Pacific.

Kelloway, E.K., 1995. Structural equation modelling in perspective. J. Organ. Behav. 16, 215-224. https://doi.org/10.1002/job.4030160304

Kim, K., Kim, S., Park, C.-Y., 2020. Food Security in Asia and the Pacific amid the COVID-19 Pandemic.

Koufteros, X.A., 1999. Testing a model of pull production: a paradigm for manufacturing research using structural equation modeling. J. Oper. Manag. 17, 467-488.

Kumar Mittal, V., Singh Sangwan, K., 2014. Development of a structural model of environmentally conscious manufacturing drivers. J. Manuf. Technol. Manag. 25, 1195-1208.

https://doi.org/10.1108/JMTM-02-2013-0012

Le, Q., Murray, S., G, L., Auckland, S., T, E., J, F., A, H., B, N., S, M., G, P., S, S., 2013. Tasmanian Food Access Research Coalition (TFARC) Research Report. https://doi.org/10.13140/2.1.3227.7286

Lindell, M.K., Whitney, D.J., 2001. Accounting for common method variance in cross-sectional research designs. J. Appl. Psychol. 86, 114.

Maniriho, A., Bizoza, A.R., 2018. Determinants of crop production in Musanze District, Northern Rwanda. East Afr. Res. Pap. Econ. Finance EARP-EF No 36.

Mohr, A., Beuchelt, T., Schneider, R., Virchow, D., 2016. Food security criteria for voluntary biomass sustainability standards and certifications. Biomass Bioenergy Spec. Issue 23rd Eur. Biomass Conf. Exhib. Held Vienna June 2015 89, 133-145. https://doi.org/10.1016/j.biombioe.2016.02.019

Montalvao, J., Van de Velde, P., 2020. COVID-19 and Food Security: Gendered Dimensions. World Bank.

Mueller, R.O., Hancock, G.R., 2001. Factor analysis and latent structure, confirmatory. Int. Encycl. Soc. Behav. Sci. 
Mumtaz, S., Parahoo, S.K., 2019. Promoting employee innovation performance. Int. J. Product. Perform. Manag.

Nyamwanza, A., Sinyolo, S., 2020. Projecting the likely impact of COVID-19 on food and nutrition security in South Africa.

Podsakoff, P.M., MacKenzie, S.B., Lee, J.-Y., Podsakoff, N.P., 2003. Common method biases in behavioral research: a critical review of the literature and recommended remedies. J. Appl. Psychol. 88, 879.

Santeramo, F.G., 2015. On the composite indicators for food security: Decisions matter! Food Rev. Int. 31, 63-73.

Sarkar, A., Qian, L., Peau, A.K., 2020. Overview of green business practices within the Bangladeshi RMG industry: competitiveness and sustainable development perspective. Environ. Sci. Pollut. Res. https://doi.org/10.1007/s11356-020-08816-y

Sassi, M., 2012. Short-term determinants of malnutrition among children in Malawi. Food Secur. 4, 593606.

Stephens, E.C., Martin, G., van Wijk, M., Timsina, J., Snow, V., 2020. Impacts of COVID-19 on agricultural and food systems worldwide and on progress to the sustainable development goals. Agric. Syst. 183, 102873.

Sumner, A., Hoy, C., Ortiz-Juarez, E., 2020. Estimates of the Impact of COVID-19 on Global Poverty. UNUWIDER April 800-9.

Taber, K.S., 2018. The use of Cronbach's alpha when developing and reporting research instruments in science education. Res. Sci. Educ. 48, 1273-1296.

Tanaka, J.S., 1987. " How big is big enough?": Sample size and goodness of fit in structural equation models with latent variables. Child Dev. 134-146.

Tefera, T., Tefera, F., 2014. Determinants of households food security and coping strategies for food shortfall in Mareko District, Guraghe Zone Southern Ethiopia. J. Food Secur. 2, 92-99.

Tehseen, S., Sajilan, S., Gadar, K., Ramayah, T., 2017. Assessing cultural orientation as a reflectiveformative second order construct-a recent PLS-SEM approach. Rev. Integr. Bus. Econ. Res. 6, 38.

Torabizadeh, M., Yusof, N.M., Ma'aram, A., Shaharoun, A.M., 2020. Identifying sustainable warehouse management system indicators and proposing new weighting method. J. Clean. Prod. 248, 119190.

Voon, J.P., Ngui, K.S., Agrawal, A., 2011. Determinants of willingness to purchase organic food: An exploratory study using structural equation modeling. Int. Food Agribus. Manag. Rev. 14, 103-120. 
Wolfson, J.A., Leung, C.W., 2020. Food Insecurity and COVID-19: Disparities in Early Effects for US Adults. Nutrients $12,1648$.

Zhang, J., He, C., Chen, L., Cao, S., 2018. Improving food security in China by taking advantage of marginal and degraded lands. J. Clean. Prod. 171, 1020-1030.

Zhou, Z., 2010. Achieving food security in China: past three decades and beyond. China Agric. Econ. Rev. 2, 251-275.

\section{Tables}

\section{Table 1: Exploratory factor analysis}

\begin{tabular}{|lll|}
\hline Kaiser-Meyer-Olkin Measure of sampling adequacy & & 0.797 \\
\hline Bartletts's test of sphericity & Approx. chi-square & 1023.256 \\
\cline { 2 - 3 } & Df & 28 \\
\cline { 2 - 2 } & Sig & 0.02 \\
\hline
\end{tabular}

Table 2: Descriptive statistics and factor analysis (within each factor) 


\begin{tabular}{|c|c|c|c|c|c|c|c|c|}
\hline \multirow[b]{2}{*}{ Determinants } & \multicolumn{5}{|c|}{ Descriptive statistics of data } & \multicolumn{3}{|c|}{ Factor loading } \\
\hline & Mean & SD & CITIC & SMC & CAID & $\begin{array}{l}\text { Factor } \\
1\end{array}$ & $\begin{array}{l}\text { Factor } \\
2\end{array}$ & $\begin{array}{l}\text { Factor } \\
3\end{array}$ \\
\hline Price of food & 4.00 & 1.09 & 0.532 & 0.533 & 0.83 & & & 0.879 \\
\hline Production & 3.64 & 1.06 & 0.698 & 0.490 & 0.82 & & & 0.755 \\
\hline Varieties of food & 3.75 & 1.01 & 0.501 & 0.506 & 0.83 & & & 0.743 \\
\hline $\begin{array}{l}\text { Proper distribution } \\
\text { channel }\end{array}$ & 3.78 & 1.06 & 0.589 & 0.554 & 0.83 & & & 0.716 \\
\hline \multirow{2}{*}{$\begin{array}{l}\text { Diverse \& variety of retails } \\
\text { options }\end{array}$} & & & & & & & & 0.734 \\
\hline & 3.76 & 1.00 & 0.503 & 0.430 & 0.81 & & & \\
\hline Purchase & 3.86 & 0.98 & 0.594 & 0.399 & 0.84 & 0.865 & & \\
\hline Processing & 3.78 & 1.03 & 0.508 & 0.532 & 0.83 & 0.796 & & \\
\hline Consumption & 3.63 & 1.02 & 0.530 & 0.675 & 0.84 & 0.854 & & \\
\hline Changing strategies & 3.89 & 1.07 & 0.569 & 0.465 & 0.82 & 0.748 & & \\
\hline $\begin{array}{l}\text { Skill, knowledge and } \\
\text { references }\end{array}$ & 3.61 & 1.01 & 0.635 & 0.598 & 0.82 & 0.856 & & \\
\hline Physical access & 3.79 & 1.04 & 0.554 & 0.597 & 0.84 & & 0.768 & \\
\hline financial access & 4.00 & 0.97 & 0.579 & 0.476 & 0.84 & & 0.778 & \\
\hline Markets/infrastructures & 3.74 & 1.02 & 0.587 & 0.479 & 0.83 & & 0.856 & \\
\hline Social supports & 2.97 & 1.09 & 0.579 & 0.529 & 0.82 & & 0.756 & \\
\hline Timing & 3.87 & 0.98 & 0.564 & 0.456 & 0.84 & & 0.890 & \\
\hline$\%$ of variance explained & & & & & & 63.089 & 62.973 & 62.097 \\
\hline $\begin{array}{l}\text { Note: } S D=\text { standard deviatic } \\
\text { correlation, CAID=Cronbach }\end{array}$ & $\begin{array}{l}\text { ITIC= } \\
\text { if itel }\end{array}$ & $\begin{array}{l}\text { rect } \\
\text { lelet }\end{array}$ & tem-to & corre & on, SN & =square & ultiple & \\
\hline
\end{tabular}

Table 3: Harman's single factor test 


\begin{tabular}{|c|c|c|c|c|c|c|}
\hline \multirow[t]{2}{*}{ Component } & \multicolumn{3}{|c|}{ Initial Eigenvalues } & \multicolumn{3}{|c|}{$\begin{array}{l}\text { Extraction Sums of Squared } \\
\text { Loadings }\end{array}$} \\
\hline & Total & $\begin{array}{l}\% \text { of } \\
\text { variance }\end{array}$ & $\begin{array}{l}\text { Cumulative } \\
\%\end{array}$ & Total & $\begin{array}{l}\% \text { of } \\
\text { variance }\end{array}$ & $\begin{array}{l}\text { Cumulative } \\
\%\end{array}$ \\
\hline Price of food & 14.866 & 49.028 & 49.028 & 14.866 & 49.028 & 49.028 \\
\hline Production & 1.589 & 5.451 & 54.479 & 1.589 & 5.451 & 54.479 \\
\hline Varieties of food & 1.468 & 4.576 & 59.055 & 1.468 & 4.576 & 59.055 \\
\hline $\begin{array}{l}\text { Proper distribution } \\
\text { channel }\end{array}$ & 1.085 & 3.621 & 62.676 & 1.085 & 3.621 & 62.676 \\
\hline $\begin{array}{l}\text { Diverse \& variety of retails } \\
\text { options }\end{array}$ & 0.986 & 3.416 & 66.092 & 0.986 & 3.416 & 66.092 \\
\hline Purchase & 0.897 & 3.073 & 69.165 & & & \\
\hline Processing & 0.765 & 2.518 & 71.683 & & & \\
\hline Consumption & 0.629 & 2.142 & 73.825 & & & \\
\hline Changing strategies & 0.576 & 1.956 & 75.781 & & & \\
\hline $\begin{array}{l}\text { Skill, knowledge, and } \\
\text { references }\end{array}$ & 0.546 & 1.864 & 77.645 & & & \\
\hline Physical access & 0.536 & 1.871 & 79.516 & & & \\
\hline financial access & 0.523 & 1.787 & 81.303 & & & \\
\hline Markets/infrastructures & 0.501 & 1.789 & 83.092 & & & \\
\hline Social supports & 0.596 & 1.853 & 84.945 & & & \\
\hline Timing & 0.580 & 1.876 & 86.821 & & & \\
\hline
\end{tabular}

Table 4. A statistical representation of Confirmatory factor analysis 


\begin{tabular}{|lllll|}
\hline \multicolumn{5}{|c|}{ Regression weights ${ }^{\mathrm{a}}$} \\
\hline Determinants & Estimate & SE & Critical ratio & Regression \\
& & & & \\
& & & & weights $^{\mathrm{b}}$ \\
\hline Price of food & 1.000 & - & - & .748 \\
\hline Production & 1.087 & 0.167 & 7.543 & 0.897 \\
\hline Varieties of food & 0.796 & 0.145 & 5.654 & 0.588 \\
\hline Proper distribution channel & 0.790 & 0.180 & 5.987 & 0.695 \\
\hline Diverse \& variety of retails options & 0.864 & 0.276 & 3.879 & 0.693 \\
\hline Purchase & 1.000 & - & - & 0.478 \\
\hline Processing & 1.656 & 0.379 & 3.976 & 0.678 \\
\hline Consumption & 2.679 & 0.376 & 3.896 & 0.785 \\
\hline Changing strategies & 2.235 & 0.689 & 4.659 & 0.887 \\
\hline Skill, knowledge and references & 1.986 & 0.877 & 3.876 & 0.560 \\
\hline Physical access & 1.000 & - & - & 0.795 \\
\hline financial access & 1.020 & 0.167 & 6.382 & 0.774 \\
\hline Markets/infrastructures & 0.987 & 0.198 & 6.087 & 0.8787 \\
\hline Social supports & 0.778 & 0.147 & 5.290 & 0.609 \\
\hline Timing & 0.870 & 0.368 & 3.867 & 0.689 \\
\hline Notes: ${ }^{-}$Unstandardized; ${ }^{b}$ Standardized. $p<0.001$ (for all coefficients) & \\
\hline & & & & \\
\hline
\end{tabular}

Table 5 Results of the hypothesis test 


\begin{tabular}{|lllll|}
\hline Hypothesis & $\begin{array}{l}\beta- \\
\text { value }\end{array}$ & $\begin{array}{l}p \text { - } \\
\text { values }\end{array}$ & Results \\
\hline "Effective utilization of food" aspects of determinants & 0.291 & 0.029 & Accepted \\
of food security are positively related to "food access." & & & \\
aspects of food security. & 0.298 & 0.011 & Accepted \\
\hline "Effective utilization of food" aspects of determinants & & & \\
$\quad \begin{array}{l}\text { of food security are positively related to "food } \\
\text { availability" aspects of food security. }\end{array}$ & & & Accepted \\
\hline H3 & $\begin{array}{l}\text { "Food availability" aspects of the determinants of food } \\
\text { security is positively related to "food access" aspects of food } \\
\text { security. }\end{array}$ & 0.128 & 0.002 & \\
\hline
\end{tabular}

\section{Figures}

\section{Lockdown impact on supply}

- Labor shortage due to travel restrictions and fear of infection

- Limited capacity of farmers to store harvested crops

- Factory or facility shutdown

- Port restrictions and congestion, leading to the spoilage of perishables and increasing food waste due to a lack of refrigerated storage

- Delays or retrieval in capital investment
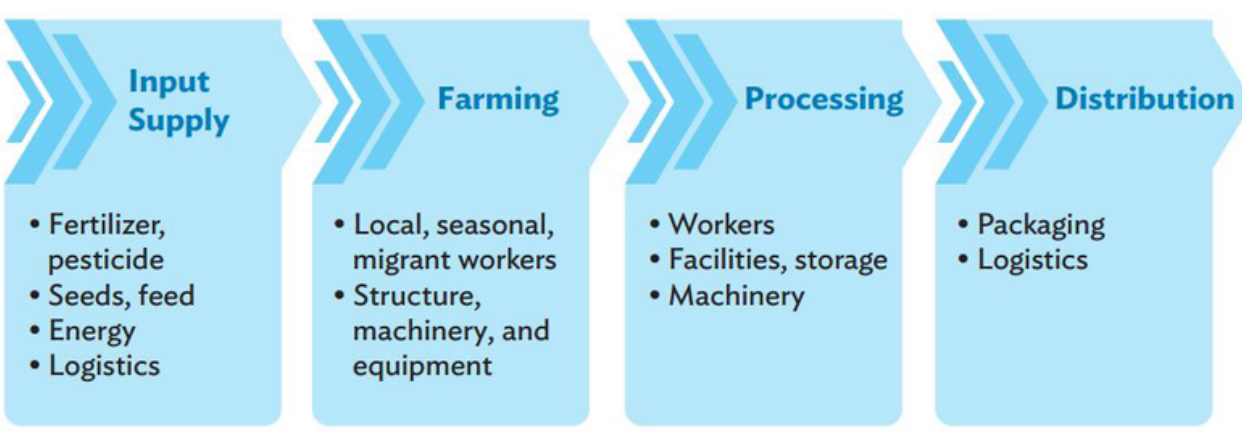

\section{Lockdown impact on demand}

- Income loss due to layoffs and furloughs

- Consumer sentiment and behavior

(e.g., panic buying, hoarding)

- Limited access to food

- Undernutrition for vulnerable groups

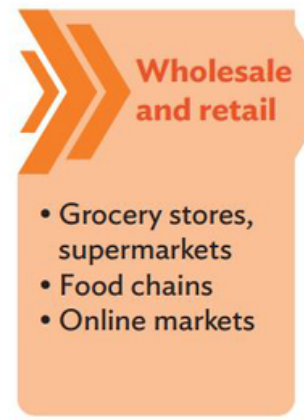

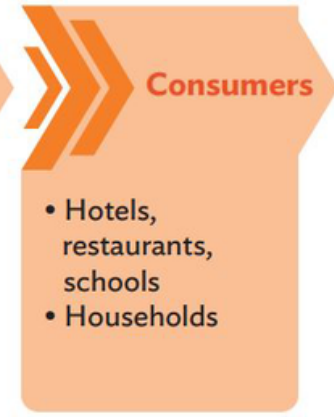

\section{Figure 1}

Possible impacts of Covid-19 on the food supply chain (Kim et al., 2020). 


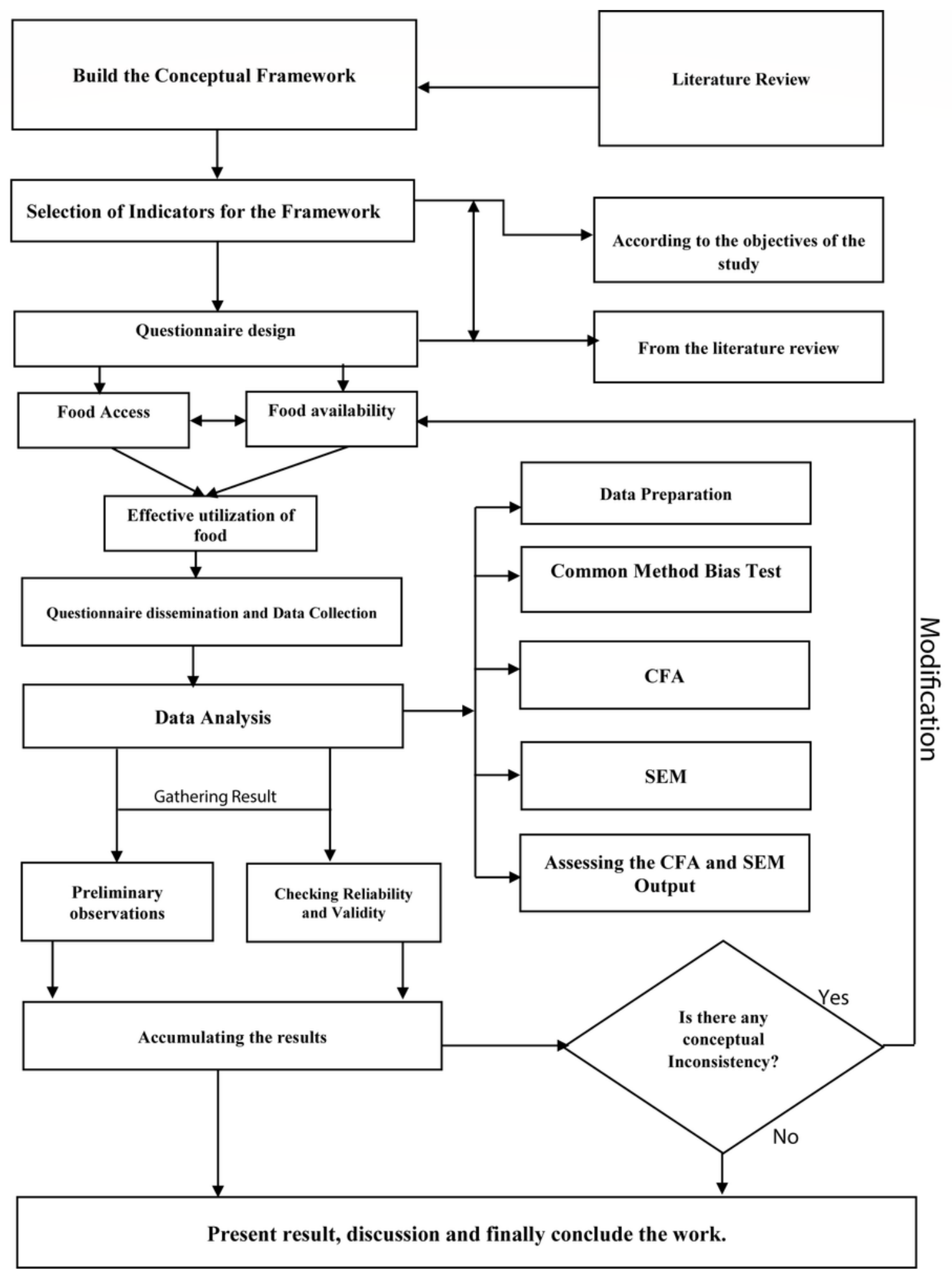

Figure 2

Steps of the current study. Adopted and modified from Sarkar et al. (2020). 


\begin{tabular}{|c|c|c|c|c|c|}
\hline & 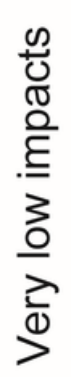 & 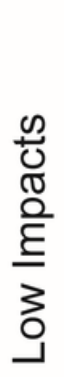 & 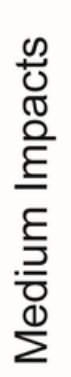 & 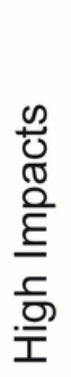 & 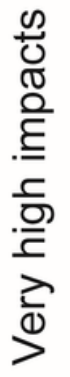 \\
\hline Price of Food & 2 & 4 & 6 & & 10 \\
\hline
\end{tabular}

\section{Figure 3}

Example of the questionnaire used.

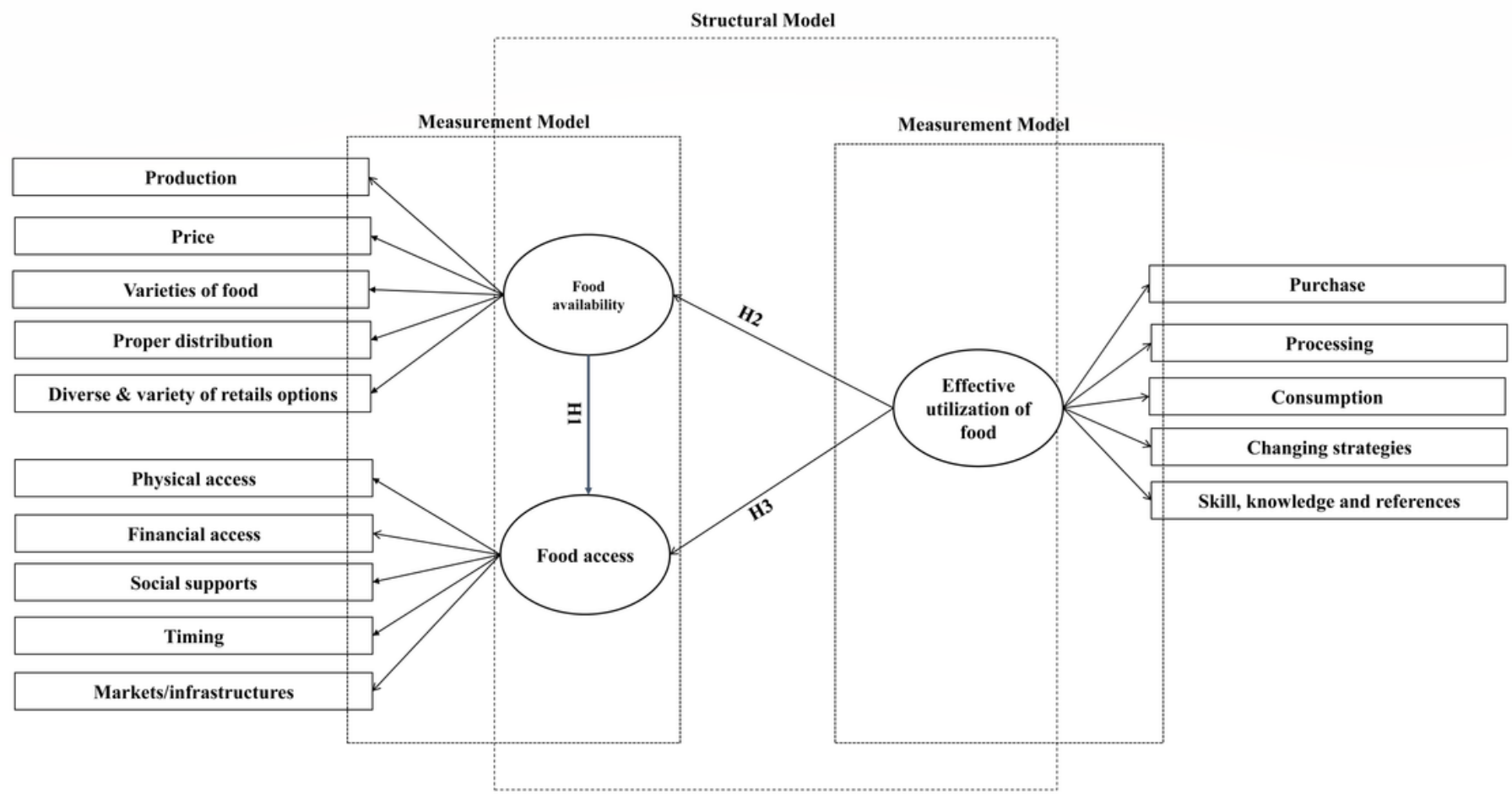

Figure 4

Complete SEM framework for the determinants of FS

\section{Supplementary Files}

This is a list of supplementary files associated with this preprint. Click to download.

- GraphicalAbstract.tif 